\title{
Selüloz Asetat/ Polivinilpirolidon Blend Membran ile Biyoetanolün Pervaporatif Dehidrasyonu
}

\author{
${ }^{* 1}$ Derya Ünlü \\ *1Mühendislik ve Doğa Bilimleri Fakültesi, Kimya Mühendisliği Bölümü, Bursa Teknik Üniversitesi, Türkiye
}

\begin{abstract}
Özet
Küresel ısınma ve yüksek petrol fiyatları, alternatif ve sürdürülebilir yenilenebilir enerji kaynakları üzerine araştırmaları artırmıştır. Biyokütleden fermantasyon yoluyla elde edilen biyoyakıtlar, fosil yakıtların yerine geçebilecek önemli alternatif yakıtlardır. Bununla birlikte, fermantasyon sonucu elde edilen ürün, yakıtın ısıl değerini büyük ölçüde azaltacak ve biyoyakıtların kullanımını sınırlayacak miktarda su içerir. Bu nedenle, biyoyakıtların dehidrasyonu önem kazanmaktadır. Pervaporasyon, düşük enerji tüketimi, atık üretmeyen çevre dostu özelliği ve azeotropik karışımları ayırmada mükemmel ayırma performansı nedeniyle biyoyakıtların dehidrasyonu için önemli bir ayırma teknolojisidir. Pervaporasyon prosesinde yüksek üretkenliğe, mükemmel seçiciliğe ve uzun süre kimyasal, termal ve mekanik dayanıma sahip membranın seçimi ve üretimi oldukça önemlidir. Membran malzemesi açısından, polimerik membranlar makul maliyetleri, üretim kolaylı̆̆ 1 ve kolay ölçeklenebilirlikleri nedeniyle büyük ilgi görmektedir. $\mathrm{Bu}$ çalışmada selüloz asetat ve polivinilpirolidon polimerleri kullanılarak blend membranlar hazırlanmıştır. Hazırlanan membranda polivinilpirolidon oranları değiştirilerek blend membranın ayırma performansına etkisi incelenmiştir. Hazırlanan membranın biyoetanolün susuzlaştırılmasında oldukça iyi ayırma performansı sergilediği görülmüştür.
\end{abstract}

Anahtar Kelimeler: Biyoetanol, dehidrasyon, membran, pervaporasyon

\begin{abstract}
The global warming and highly petroleum prices have increased the studies on renewable energy sources. Biofuels, which obtained from biomass by using fermentation, are important alternative fuels to fossil fuels. However, the obtained product from fermentation contains water. This is resulted in decrement the heating value of fuel and limits the applications of biofuels. Therefore, dehydration of biofuels gains importance. Pervaporation is a significant separation technology to dehydration of biofuels because of its low energy consumption, environmental friendly properties and excellent separation performance in separating azeotropic mixtures . In the pervaporation process, the selection and production of the membrane with high productivity ability, excellent selectivity and chemical, thermal and mechanical stability is rather important. The polymeric membranes receive a great deal of attention because of their low cost, easy production and easy scalability. In this study, cellulose acetate and polyvinylpyrrolidone polymers were used for the preparation of blend membranes. The effect of blend membrane on separation performance was examined by changing polyvinylpyrrolidone ratios . It can be seen that the prepared membrane has exhibit rather good separation performance in the dehydration of bioethanol.
\end{abstract}

Key words: Bioethanol, dehydration, membrane, pervaporation

*Sorumlu Yazar: Adres: Mühendislik ve Doğa Bilimleri Fakültesi, Kimya Mühendisliği Bölümü, Bursa Teknik Üniversitesi, 16310, Bursa TÜRKIYE. E-mail adres: derya.unlu@btu.edu.tr, Telefon: +902243003828, Fax: +902243003419 


\section{Giriş}

Artan enerji krizi ve çevre kirliliği, endüstriyel gelişmeler ve insan sağlığı için dünya çapında iki temel tehdit haline gelmiştir. Çevre dostu, yeni alternatif enerji kaynaklarının araştırılmasına acil ihtiyaç vardır. Şeker kamışı ve selüloz biyokütlesi gibi yenilenebilir hammaddelerin fermantasyonundan üretilen biyoetanol, geleneksel fosil yakitların yerini alabilecek temiz ve umut vaat eden alternatif bir yakıt olarak kabul edilmiştir. Son yıllarda, biyoetanol sera gazları ve zararlı azot veya sülfür oksit emisyonlarını azaltmak ve benzinin daha temiz yanmasına yardımcı olmak için oktan arttırıcı yakıt katkı maddesi olarak yaygın şekilde kullanılmaktadır. Endüstriyel ölçekte, etanol genellikle fermantasyon veya etilen hidrasyonu ile üretilir, ancak her ikisinde de ürünler seyreltik sulu çözeltiler halinde elde edilir. Bu nedenle, etanolü sulu çözeltiden ayırmak, konsantre hale getirmek ve oluşan azeotropik karışımdan suyu etkili bir şekilde uzaklaştırmak için etkili bir teknolojinin araştırılması biyoetanol endüstrisinde önemli bir konudur [1-3].

Fermantasyon karışımından etanolün konsantre edilmesi gibi yakın kaynama noktalı veya azeotropik karışımların ayrılması sırasında, pervaporasyon, ilave kimyasal ve çözücülerin kullanılmaması nedeniyle düşük maliyeti, distilasyon gibi geleneksel yöntemlere göre düşük enerji tüketimi ve 1lımlı koşullar altında çalışıldığında fermantasyon sistemindeki mikro organizmalar üzerindeki etkiyi en aza indiren belirgin avantajlar göstermiştir [3-4].

Pervaporasyonda membran, membran yüzeyinde yüksek çözünürlüğe ve difüziviteye sahip bileşenin difüzyonuna izin verir. Pervaporasyonda taşınım, çözünme-difüzyon mekanizması ile gerçekleşir. Bu kütle aktarım mekanizması üç ana aşamadan oluşur: (a) seçici bileşenin membran üzerinde emilmesi, (b) seçici bileşenin membran boyunca difüzyonu ve (c) seçici bileşenin geçen akım tarafından desorpsiyonu. Pervaporasyonda taşınım için itici güç, buhar basıncı farkıdır. Bu kuvvet, besleme tarafi atmosferik basınç altındayken geçen akım tarafına düşük vakum basıncı uygulanarak oluşturulur [5-8].

Pervaporasyonda membran malzemesi seçimi oldukça önemlidir. İyi bir membran yüksek üretkenliğe, mükemmel seçiciliğe ve uzun vadeli kimyasal, termal ve mekanik dayanıma sahip olmalıdır. Membran malzemesi açısından, polimerik membranlar, düşük maliyetleri, üretim kolaylıkları ve yüksek ölçeklenebilirlikleri nedeniyle büyük ilgi görmektedir [4].

Selüloz asetat, doğal ve yenilenebilir özelliklerinin yanı sıra üstün film oluşturma kabiliyeti nedeniyle son yıllarda pervaporasyon ile ayırmada da popüler bir malzeme haline gelmiştir. Ancak çözücü olarak dimetilformamid (DMF) kullanılarak hazırlanan saf SA membranın geçirgenlik akısının, genellikle nispeten düşük olduğu görülmüştür. İdeal bir ayırma performansı elde etmek için (daha yüksek akı ve seçicilik), genellikle membranlar modifiye edilir. Çeşitli modifikasyon yöntemleri arasında, harmanlama (blend yapma) yaygın olarak kullanılan bir tekniktir ve çok yönlülüğü ve basitliği nedeniyle tercih edilmektedir. Polimerler uygun bir şekilde eşleştirilirse, iki polimerin olumlu bir sinerjik etkisi elde edilebilir. Blend membranların pervaporasyon performansı, esas olarak bir araya getirilen polimerlerin karışabilirliğine ve ayrılmak istenilen bileşenlerin membranda çözünürlüğü ve difüzyon davranışına bağlıdır [9]. Bu çalışmada selüloz asetata polivinil pirolidon polimeri eklenmiştir. PVP polimeri hidrofilik yapısından sorumlu amid ve karbonil gruplarına sahiptir. Bu gruplar, membran ile su arasında 
hidrojen bağı oluşumunu sağlar. Polivinil pirolidon ilavesi, polimerik membran karışımının kristallik derecesini düşürür ve membran matrisi arasındaki difüzyon boşluklarını artırır. $\mathrm{Bu}$ durum sorpsiyon ve difüzyon derecesini artırır ve ayırma performansını etkiler [10].

Bu çalışmada hazırlanan Selüloz asetat / polivinil pirolidon blend membranın pervaporatif ayırma performansı etanol/su karışımının dehidrasyonunda incelenmiştir. Hazırlanan blend membranda kullanılan polimerlerin uyumluluğu SEM analizi ile görüntülenmiştir. Polivinil pirolidon yükleme oranının, besleme konsantrasyonun ve sıcaklığın ayırma performansına etkisi incelenmiştir.

\section{Malzeme ve Yöntem}

\subsection{Malzemeler}

Membran hazırlama da kullanılan polimerlerden Selüloz Asetat Acros Organic'den, Polivinil pirolidon Sigma Aldrich firmalarından temin edilmiştir. N,N-Dimetilformamid, Fisher kimyasaldan alınmıştır. \%99 saflıkta etanol Merck'ten temin edilmiştir.

\subsection{Membran Sentezi ve Karakterizasyonu}

İlk olarak belirlenen miktarda selüloz asetat, N,N-Dimetilformamid çözücüsünde oda sıcaklığında çözülerek homojen polimer çözeltisi elde edilmiştir. Hazırlanan polimer çözeltisine belirli oranlarda (toplam çözelti ağırlığının \%1, \%2 ve \%3) polivinil pirolidon eklenerek homojen bir çözelti elde edilene karıştırılmıştır. Elde edilen blend polimerik membran çözeltisi cam petri kabına dökülerek $90^{\circ} \mathrm{C}$ sıcaklıkta etüvde kurutulmuştur. Kuruyan membran kullanıma hazır hale gelmiştir. Membranda kullanılan polimerlerin uyumluluğu ve karışabilirliği SEM analizi yaparak belirlenmiştir.

\subsection{Etanolün Pervaporatif Dehidrasyonu}

Etanolün pervaporatif dehidrasyonu laboratuar ölçekli pervaporasyon sisteminde gerçekleştirilmiştir. Sistem, membranın ve besleme karışımının yer aldığı membran hücresi, karışımın homojenizasyonu için mekanik karıştırıcı, alt akımda düşük basıncı sağlamak için vakum pompası ve membrandan geçen akımın toplandığı soğutucu kapanlardan oluşmaktadır. Membranın ayırma performansı akı ve ayırma faktörü ile belirlenmiştir. Akı ve ayırma sırasıyla Eşitlik 1 ve Eşitlik 2 kullanılarak hesaplanmıştır.

$$
\begin{aligned}
\mathrm{J} & =\frac{\mathrm{m}}{\mathrm{A} \cdot \mathrm{t}} \\
\alpha & =\frac{\mathrm{y}_{\mathrm{su}} / \mathrm{y}_{\mathrm{etanol}}}{\mathrm{x}_{\mathrm{su}} / \mathrm{x}_{\mathrm{etanol}}}
\end{aligned}
$$

Eşitlik 1'de m geçen akıda toplanan numune miktarını, A alanı, $\mathrm{t}$ ise süreyi ifade etmektedir. 
Eşitlik 2'de ise y geçen akım, x ise beslemedeki ağırlıkça yüzdeyi göstermektedir.

Bileşenlerin konsantrasyonu refraktometre ile belirlenmiştir.

\section{Sonuçlar}

\subsection{SEM Analizi}

SEM analizi, selüloz asetat/ polivinil pirolidon blend membranından alınan örnekler ile yapılmıştır. Şekil 1'de blend membrandan alınan kesit görüntüsü verilmiştir.

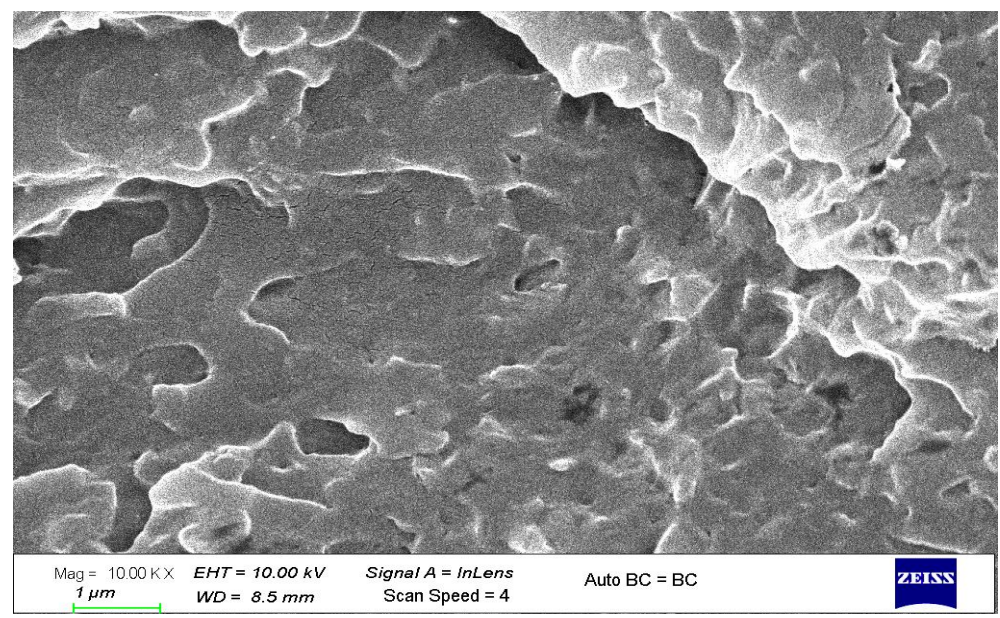

Şekil 1. Selüloz Asetat/Polivinil pirolidon Blend Membranın Kesit Görüntüsü

SEM görüntüleri iki polimerinde çok iyi karıştığını, faz ayırımı gözlenmediğini ve uyumlu polimerik hareket sergilediğini göstermiştir. Tüm bunlar polimerler arası gerçekleşen moleküler etkileşimin sonucudur. İki polimer arasında kuvvetli etkileşim oluşmuştur ve böylece faz ayrımı oluşmamıştır. Sonuç olarak homojen blend filmler elde edilmiştir [12].

\subsection{Pervaporatif Dehidrasyon Sonuçları}

\subsubsection{Polivinil pirolidon yükleme oranının ayırma performansına etkisi}

Şekil 2, Selüloz Asetat/Polivinil pirolidon blend membranlarındaki poli(vinil pirolidon) içeriğinin etanolün pervaporatif dehidrasyonu üzerindeki etkisini göstermektedir. 


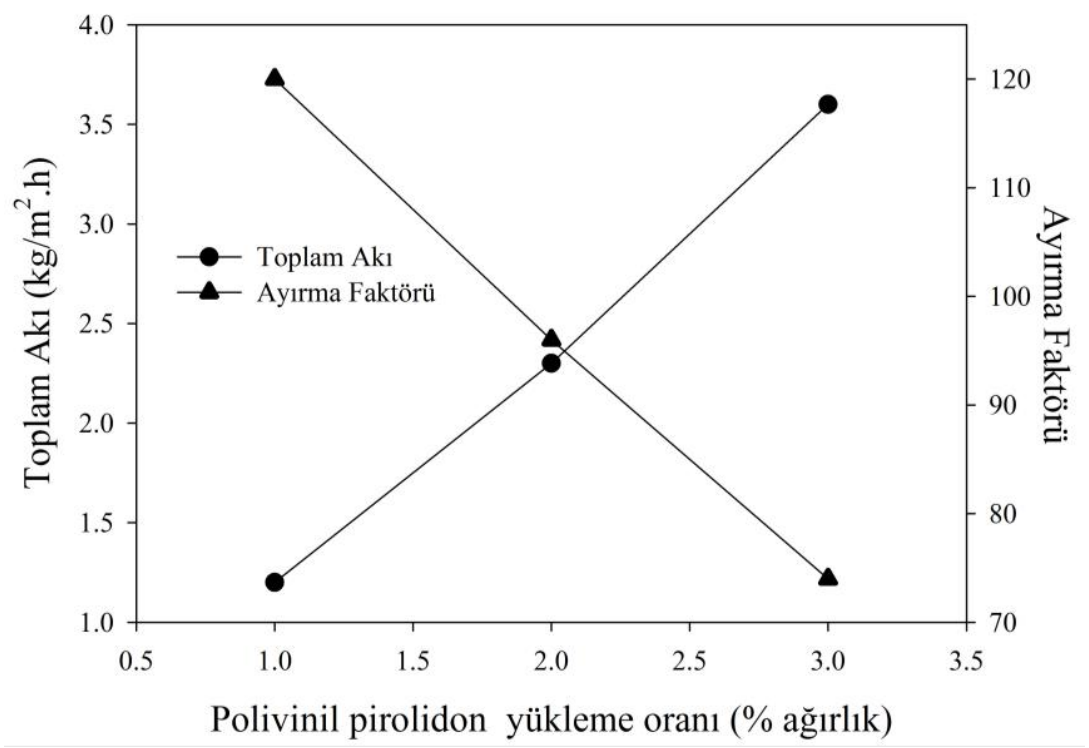

Şekil 2. Polivinil pirolidon yükleme oranının ayırma performansına etkisi $\left(35^{\circ} \mathrm{C}\right.$, ağırlıcça $\% 5$ besleme su konsantrasyonu)

Polivinil pirolidon içeriği arttıkça akının arttı̆̆ı, ayırma faktörünün azaldığı görülmektedir. Selüloz asetata Polivinil pirolidon ilave edilmesi, selüloz asetatın polimer zincirlerinin düzenini, kristalinitesini bozarak, membranın yoğunluğunda azalmaya ve buna bağlı olarak da şişme derecesinde artışa neden olmaktadır. Sonuç olarak membranın kristalinitesi azalmakta Polivinil pirolidon ilavesi ile membranın serbest hacmi artmaktadır. Öte yandan, Polivinil pirolidon eklenmesi, Polivinil pirolidonun güçlü polariteye ve hidrofilik gruplara sahip olmasından dolayı membranların hidrofilikliğini önemli ölçüde arttırmaktadır. Dolayısıyla membran ve su arasında hidrojen bağı oluşumu artmaktadır. Bu nedenle, su ve membran arasındaki etkileşim artar. Bütün bunlar suyun sorpsiyonunda bir artışa neden olur. Ancak Polivinil pirolidon içeriğgindeki artış sorpsiyon seçiciliğinde artışa neden olurken difüzyon seçiciliğinde azalmaya neden olur. Difüzyon seçiciliğindeki azalma da ayırma faktörünün azalması ile sonuçlanır. Çünkü artan şişme derecesi, membranların serbest hacminde artışa yol açarak etanolün difüzyonuna da izin verir. $\mathrm{Bu}$ nedenle difüzyon seçiciliği Polivinil pirolidon içeriği arttıkça önemli ölçüde azalmıştır. Sonuç olarak, artan Polivinil pirolidon içeriği ile hem membran ile bileşen arasındaki etkileşimin artması hem de şişme derecesinin artması ayırma faktörünü azaltmış, geçirgenlik akısını arttırmıştır [13-15]. Ağırlıkça \%1 Polivinil pirolidon yüklenmiş blend membranın akı ve ayırma faktörü $1.18 \mathrm{~kg} / \mathrm{m}^{2} . \mathrm{h}$ ve 117 iken; Polivinil pirolidon oranı \%3'e çıkarıldığında akı ve ayırma faktörü değeri $3.6 \mathrm{~kg} / \mathrm{m}^{2}$.h ve 74 olmuştur.

\subsubsection{Besleme su konsantrasyonunun ayırma performansına etkisi}

Ağırlıkça \%1 Polivinil pirolidon içeren Selüloz asetat-Polivinil pirolidon blend membranı kullanılarak $35^{\circ} \mathrm{C}^{\prime}$ de test edilen etanolün pervaporatif dehidrasyonu sonuçları Şekil 3'te gösterilmektedir. 


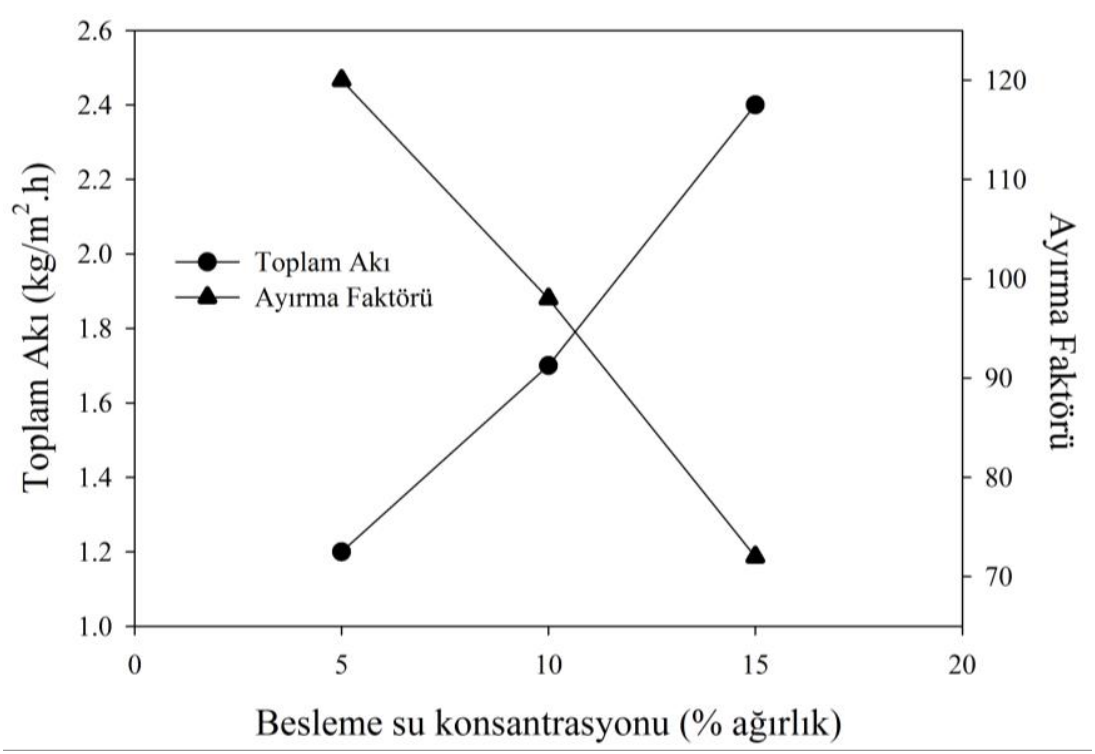

Şekil 3. Besleme su konsantrasyonunun ayırma performansına etkisi (Ağırlıkça \%1 Polivinil pirolidon yüklü membran, $\left.35^{\circ} \mathrm{C}\right)$

Elde edilen sonuçlar besleme karışımındaki su konsantrasyonu arttıkça toplam akının 1.19 $\mathrm{kg} / \mathrm{m}^{2}$.h'den $2.41 \mathrm{~kg} / \mathrm{m}^{2}$.h'ye yükseldiğini, seçiciliğin ise 118 'den 72'ye düştüğünü göstermektedir. Yüksek akı değeri Polivinil pirolidonun suya karşı kuvvetli ilgisinden kaynaklanmaktadır. Beslemedeki su konsantrasyonu arttıkça, membranın amorf bölgeleri daha fazla şişer ve polimer zincirleri daha esnek hale gelir, bu da hem suyun hem de etanolün moleküllerinin membrandan daha kolay difüzyonuna neden olur. $\mathrm{Bu}$ nedenle, suyun ve etanolün geçiş akısı artar, ayırma faktörü azalır $[13,16]$.

\subsubsection{Sıcaklı̆̆ın ayırma performansına etkisi}

Sıcaklık, pervaporasyonda önemli bir çalışma parametresidir çünkü hem sorpsiyon hem de difüzyon işlemini etkiler. Dolayısıyla membranların performansını da önemli ölçüde etkilemektedir. Şekil 4, sıcaklığın $35-55^{\circ} \mathrm{C}$ aralığında pervaporasyon performansı üzerindeki etkisini göstermektedir. 


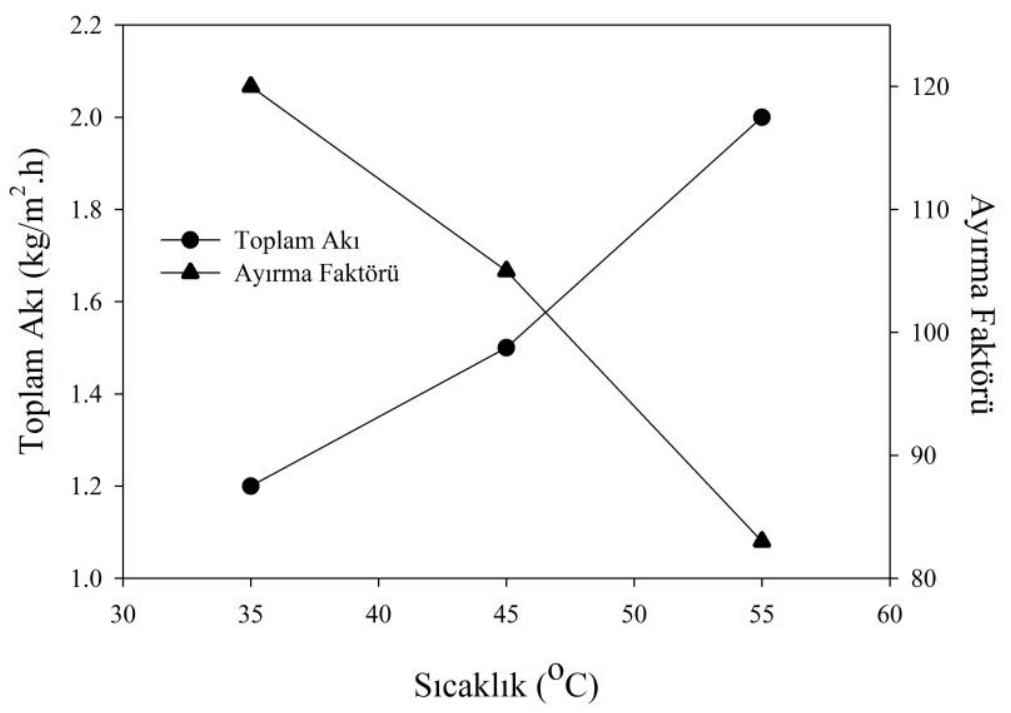

Şekil 4. Sıcaklığın ayırma performansına etkisi (Ağırlıkça \%1 Polivinil pirolidon yüklü membran, ağırlıkça \%5 besleme su konsantrasyonu)

Artan sıcaklıkla geçiş akısı artarken, ayırma faktörü azalmıştır. Bunun nedeni, sıcaklık arttıkça polimer zincirlerin titreşim frekansının ve zincir hareketliliğinin artması ve bunun sonucunda da membranın şişme derecesinin artmasıdır. Membranın şişme derecesinin artması ile membranların serbest hacmi artar. Bunun yanında sıcaklık arttıkça, besleme karışımındaki tüm bileşenlerin buhar basıncı artmış ancak geçen akım tarafındaki buhar basıncı etkilenmemiştir. Sonuç olarak, bu sıcaklık farkının yarattığı buhar basıncı farkı da itici güç oluşturur. Tüm bu etkilerden dolayı hem sorpsiyon seçiciliği hem de difüzyon seçiciliğinin azalması ile geçirgenlik akısı artmış, ayırma faktörü azalmıştır. Şişme derecesinin artması difüzyonu kolaylaştırmış dolayısıyla akı artmıştır. Ancak sıcaklıkla hareketliliğin artmasıyla genişleyen difüzyon kanalları su ile birlikte etanolünde taşınımının gerçekleşmesini sağlamış, dolayısıyla akı artarken ayırma faktörü düşmüştür [14]. Sicaklık $35^{\circ} \mathrm{C}^{\prime}$ den $55^{\circ} \mathrm{C}^{\prime}$ ye yükseldiğinde akı değeri $1.2 \mathrm{~kg} / \mathrm{m}^{2} \cdot \mathrm{h}^{\prime}$ ten 2 $\mathrm{kg} / \mathrm{m}^{2} . \mathrm{h}^{\prime} \mathrm{a}$ artarken, ayırma faktörü değeri 120'den 83'e düşmüştür.

\section{Genel Sonuçlar}

Biyoetanolün sentezi sonucunda yapısında kalan su biyoetanolün yakıt özelliklerini etkilediğinden biyoyakıt olarak kullanımına engel oluşturmaktadır. Bu nedenle ortamdaki suyun uzaklaştırılması gerekmektedir. Ancak etanol ve suyun azeotrop oluşturması geleneksel ayırma yöntemleri ile ayrılmasını zorlaştırmaktadır. Bu nedenle bu çalışmada etanolün dehidrasyonu için yenilikçi bir ayırma prosesi olan pervaporasyon prosesi önerilmiştir. Membran malzemesi olarak selüloz asetat ve polivinil pirolidonun seçildiği blend membranın ayırma performansı Polivinil pirolidonun katkı oranı, besleme konsantrasyonu ve operasyon sıcaklığına bağlı olarak incelenmiştir. Polivinil pirolidonun membranın hidrofilikliğini arttırdığı buna bağlı olarak da akıyı arttırıp ayırma faktörünü düşürdüğü bulunmuştur. Besleme su konsantrasyonunun artışı ise membran ile suyun temasının artmasını sağlayarak membranın şişme derecesini arttırdığı ve buna bağlı olarak da akının artarak, ayırma faktörünün azaldığı sonucuna varılmıştır. Operasyon 
sıcaklığı arttıkça ise sıcaklığın bileşenlerin buhar basıncını arttırması ve membrandaki polimer zincirlerinin hareketliliğini arttırması ile akının artarak ayırma faktöründe azalmaya yol açtığı görülmüştür. Yapılan deneysel çalışmalar sonucunda optimum çalışma koşullarının \%1 Polivinil pirolidon yüklü membran ile $35^{\circ} \mathrm{C}^{\prime}$ de ağırlıkça $\% 5$ besleme su konsantrasyonunda elde edildiği görülmüştür. En iyi ayırma veriminin $\% 5$ su konsantrasyonunda elde edilmesi bu konsantrasyonda azeotrop oluşturan su ve etanol için önerilen ayırma prosesi pervaporasyonun uygunluğunu göstermektedir. Optimum koşullarda elde edilen akı ve ayırma faktörü değerleri ise sirasiyla $1.2 \mathrm{~kg} / \mathrm{m}^{2} . \mathrm{h}$ ve 120 'dir.

\section{Referanslar}

[1] Cao Z, Xia C, Jia W, Qing W, Zhang W. Enhancing bioethanol productivity by a yeastimmobilized catalytically active membrane in a fermentation-pervaporation coupling process. J Membr Sci 2020; 595:117485.

[2] Baeyens J, Kang Q, Appels L, Dewil R, Lv Y, Tan T. Challenges and opportunities in improving the production of bio-ethanol. Prog Energy Combust 2015; 47: 60-88.

[3] He X, Wang T, Huang J, Chen J, Li J. Fabrication and characterization of superhydrophobic PDMS composite membranes for efficient ethanol recovery via pervaporation. Sep Purif Technol 2020; 116675.

[4] Xu YM, Japip S, Chung TS. UiO-66-NH2 incorporated dual-layer hollow fibers made by immiscibility induced phase separation (I2PS) process for ethanol dehydration via pervaporation. J Membr Sci 2019; 117571.

[5] Huang RYM. Pervaporation Membrane Separation Processes. 1st ed. Amsterdam: Elsevier; 1991.

[6] Smitha B, Suhanya D, Sridhar S, Ramakrishna M. Separation of organic-organic mixtures by pervaporation - a review. J Membr Sci 2004; 241(1):1-21.

[7] Wijmans JG, Baker RW. The solution-diffusion model: a review. J Membr Sci 1995; 107(1-2):1-21.

[8] Austria HFM, Lecaros RLG, Hung WS, Tayo LL, Hu CC, Tsai HA, Lai JY. Investigation of salt penetration mechanism in hydrolyzed polyacrylonitrile asymmetric membranes for pervaporation desalination. Desalination 2019; 463:32-39.

[9] Wu H, Fang X, Zhang X, Jiang Z, LiB, Ma X. Cellulose acetate-poly(N-vinyl-2pyrrolidone) blend membrane for pervaporation separation of methanol/MTBE mixtures. Sep Purif Technol 2008; 64(2):183-191.

[10] Zhang XH, Liu QL, Xiong Y, Zhu AM, Chen Y, Zhang QG. Pervaporation Dehydration of Ethyl Acetate/Ethanol/Water Azeotrope Using Chitosan/Poly (vinyl pyrrolidone) Blend Membranes. J Membr Sci 2009; 327:274-280.

[11] Zhu Y, Xia S, Liu G, Jin W, Preparation of ceramic-supported poly(vinyl alcohol)-chitosan composite membranes and their applications in pervaporation dehydration of organic/water mixtures. J Membr Sci 2010; 349:341-348.

[12] Miyashita Y, Suzuki T, Nishio Y. Miscibility of cellulose acetate with vinyl polymers. Cellulose 2002; 9: 215-223.

[13] Sunitha K, Kumar YVLR, Sridhar S. Effect of PVP loading on pervaporation performance of poly(vinyl alcohol) membranes for THF/water mixtures. J Mater Sci 2009; 44(23):62806285. 
[14] Zhang XH, Liu QL, Xiong Y, Zhu AM, Chen Y, Zhang QG. Pervaporation dehydration of ethyl acetate/ethanol/water azeotrope using chitosan/poly (vinyl pyrrolidone) blend membranes. J Membr Sci 2009;327(1-2):274-280.

[15] Lu J, Nguyen Q, Zhou J, Ping ZH. Poly(vinyl alcohol)/poly(vinyl pyrrolidone) interpenetrating polymer network: Synthesis and pervaporation properties. J Appl Polym 2003; 89(10):2808-2814.

[16] Zhu T, Luo Y, Lin Y, Li Q, Yu P, Zeng M. Study of pervaporation for dehydration of caprolactam through blend NaAlg-poly(vinyl pyrrolidone) membranes on PAN supports. Sep Purif Technol 2010; 74(2): 242-252. 